\title{
Curriculum reformation of e-commerce based on MOOC
}

\author{
Rui Zhang*, Hongyan Li, Junhui Fan \& Huixia Ren \\ School of Management, Shanghai University of Engineering Science, Shanghai, China
}

\begin{abstract}
Faced with emerging problems in the teaching process of e-commerce course, such as unitary teaching method, obsolete teaching content, weak practicality, unitary test measurement, and so on, this paper proposes the curriculum reformation of e-commerce based on MOOC to deal with the current e-commerce teaching difficulties that exist. By MOOC mode applications, as well as pilots in the usual teaching classroom, this paper gives the reform program of e-commerce courses and designs many other aspects, such as the refinement of curriculum teaching design, enhanced multi-interactive, process-oriented evaluation mode. Through the pilot, some certain results have achieved. The curriculum reformation of e-commerce based on MOOC has promoted students to learn effectively, and improve the teaching quality of e-commerce knowledge of the course, to a certain extent.
\end{abstract}

Keywords: e-commerce; MOOC; curriculum reformation

\section{INTRODUCTION}

With the continuous development of information technology, e-learning mode has gradually become the mainstream way of self-study among college students. As requirements of students for learning personalization, diversification and flexibility is increasingly higher, the traditional face-to-face teaching mode cannot satisfy the needs of students. Based on computer technology, trade and economics, the curriculum reformation of e-commerce has been widely concerned. In recent years, e-commerce has penetrated into all aspects of lives. However, the traditional e-commerce course is often limited to textbooks, and its structure of system is relatively backward. The lack of communication between teachers and students has been hindering the improvement of teaching efficiency and student learning. Currently, MOOC model is able to effectively address these problems. By using large open online courses, MOOC can improve the ability of teachers to use new teaching tools and promote communication between teachers and students. Meanwhile, it can allow students to arrange their time and achieve personalized learning.

*Corresponding author: rui5028369@126.com

\section{MOOC}

\subsection{The characteristic of MOOC}

MOOC, namely Massive Open Online Course, is a combination of information technology, mobile Internet and high-quality education, which can share knowledge from the excellent digital educational resources around the world through this network terminal platform. Thus MOOC not only provides free quality resources to learners, but also provides a complete learning experience[1]. In September 2008, Canadian scholar George Siemens and Stephen Downes opened the first door MOOC course named as "Connectivism and Connective Knowledge Online Course". This course not only manifested open teaching ideas, but also supported learners to participate in various forms of learning [2].

Relatively speaking, MOOC has made considerable progress than existing national quality courses, video open class, and resource sharing lessons on teaching function (see Table 1).

In a word, MOOC has several features below:

\subsubsection{Various teaching tools and resources}

MOOC course largely integrated traditional classroom and online classes. MOOC is not just kind of traditional one-way transfer of knowledge. MOOC also 
Table 1.Comparison of three major e-learning modes [3].

\begin{tabular}{llll}
\hline & Resource complete class & Video open class & MOOC \\
\hline Websites & National quality courses & Icourses & Courera, EDX, Udacity \\
Form & Resource sharing, etc. & $\begin{array}{c}\text { The courses of famous univer- } \\
\text { sities, etc. }\end{array}$ & $\begin{array}{c}\text { High-quality free open network course, } \\
\text { around the whole world, etc. }\end{array}$ \\
Advantage & A complete range of courses, etc. & $\begin{array}{c}\text { Break traditional teaching } \\
\text { mode, interaction, etc. }\end{array}$ & $\begin{array}{c}\text { Resource sharing, micro course, receive } \\
\text { a certificate, communication, etc. }\end{array}$ \\
Disadvantage & Ignore the teaching organization & $\begin{array}{c}\text { Not match the actual teaching } \\
\text { hours }\end{array}$ & Need of platform and policy support
\end{tabular}

integrate digital resources around the course content in various forms by different techniques and social networking tools to achieve diversely multi-dimensional teaching.

\subsubsection{Complete course structure}

Although MOOC course has divided knowledge into fine block units professionally, its imparted knowledge is complete and systematic. By publishing course information, instructors, course outlines, etc., on the platform, MOOC is convenient for students to elective. Also, Weekly timed release of video teaching materials, assignments and organizing online discussion are essential routine service. So students can independently watch video materials, ask questions and participate in the discussion, the timely completion of the job and so on. It also provides learners with a variety of user communication community, which focuses on student learning support service and pours attention into learning experience of students. Students who complete the course can receive a certificate, or get credit by selecting specific courses.

\subsubsection{Learning at anytime and anywhere}

MOOC breaks the traditional online classroom curriculum time and space constraints, divides the knowledge into fine block units to facilitate student learning by subject, and enable students to be convenient to use fragmented time to watch and learn, so as to leave reasonable time to the learners for reflection, discussion, digestion and absorption in order to strengthen teaching effectiveness. At the same time, learners can be learning in anywhere at their own pace and can get timely learning feedback, and timely record personal learning behaviours and processes.

\subsubsection{Real-time communication and communication [4]}

A lot of participations and communication is one of the reasons why MOOC is able to capture many learners' attention in an intensely short time. MOOC have a strong discussion area where all students can participate in the course of study by expressing their views in forums, sharing of information, mutual leak filled and brainstorming to help each other. Instructors participate in the discussing area through social networking platform, by real-time tracking to give guidance and answers to achieve timely feedback to learners. This learning model will encourage and guide students to be more active to learn and think so that learners have a high degree of autonomy in order to effectively improve their learning outcomes.

\subsection{The development of $\mathrm{MOOC}$}

Since 2012, MOOC develops rapidly as increasing educational institutions worldwide are working in participation and development of MOOC. A series of new ideas in MOOC, including online learning, anytime learning, interactive learning, reversal learning and social learning, attract many of the world-renowned colleges to join in this reform wave. Three open online course platforms include Courera from Stanford University, EDX from Harvard University and MIT, Udacity from Google and Microsoft, and they set their own learning and management system. At present, in addition to institutions of higher learning, the University of Hong Kong will put part of projects on the Coursera platform, Tsinghua University has officially joined the United States in the EDX think education platform, and NetEase-open-class, Tencent micro classroom, Baidu marketing university, Taobao students, etc. have come into use[5].

Currently, there are two modes when it comes to MOOC, cMOOC mode and XMOOC mode. Based on the associated learning theory, the former focuses on the construction of knowledge and creativity, emphasizing creativity, autonomy and social network learning. Based on behavioral learning theory, the latter focuses on knowledge dissemination and replication, emphasizing video, assignments and tests learning. Therefore, experts and scholars unfold the study of MOOC mainly around its origin and development, and the impacts on traditional education, while MOOC provide platforms and technologies as well as environmental development and the teaching reform based on the MOOC. In contrast, there are a number of articles discussed and presented about MOOC origins and development process. $\mathrm{Li}[6]$, Zhang[7], and $\mathrm{He}[8]$ combed the production, development and current situation of MOOC from different depths in their respective articles. According to his MOOC teaching experience, Head[9] analysed this innovative technology's application and development in the United States general education. Wang[10] explored the impact of MOOC development on higher education, and believed that the opportunities and challenges coexist. Zhou et al.[11] discussed the necessity of the MOOC 
construction in China's universities and proposed main countermeasures and suggestions about the implementation of MOOC teaching in a profession.

Researches about providing platforms and technologies environment by MOOC are the earliest and most common research topics in the related researches. Based on systematic analysis of MOOC, $\mathrm{Wu}[12]$ and Cui[13] regarded the cloud learning environment as an entry point, and proposed the cloud learning environment framework under MOOC mode. Ma et al.[14] researched MOOC characteristics from the perspective of technology and explored the technical support, platform architecture and business model required by MOOC education platform. Wang et al.[15] drew the blended learning approach from the perspective of ecological description, constructed MOOC teaching ecological model and designed related educational technology training curriculum system based on the MOOC model. Foreign literatures in this area put more attention on MOOC's technology and learner or the relationship with the study evaluation [16-17].

With the further development of MOOC, MOOC-based education reform has also been put on the agenda. Zhang et al.[18] believed that the rising MOOC reflects the change of the educational concept, from the classroom to the school, from teaching to learning and noted that MOOC will get new development from the following aspects in the future: learning interaction, learning evaluation, special learning support. Yang et al.[19] proposed MOOC 3.0 new ideas required by "quality, ability, knowledge" and discussed "three-dimensional MOOC" for teaching in the network engineering profession of the local colleges. However, more researches unfolded about one kind of curriculum reform of college. Ma et al.[20], $\mathrm{Hu}$ et al.[21], and Whitmer et al.[22] discussed the inspiration of MOOC on language class teaching, such as English teaching, and set up related initiatives. Chi et al[23], Liu[24], Yuan et al.[25] analyzed the situation, features and advantages of MOOC, and discussed computer courses teaching methods combined with the practical needs of teaching reform in college computer courses.

Thus, as a new online teaching model, MOOC has received widespread attention, and has been applied to many types of courses among the teaching reform. With the maturity of the MOOC industry chain, the influence of MOOC will become more and more giant in the future, which may bring greater impact to the traditional higher education, in particular to teaching in colleges.

\section{STATUS OF E-COMMERCE COURSE IN UNIVERSITIES}

E-commerce is one of the new cross-discipline which in itself involves a wide range of disciplines such as computer, economics, management and marketing.
With the rapid development of e-commerce, this subject also put forward new demands to e-commerce teaching in universities. Currently, e-commerce in university teaching is mainly characterized by the following status.

\subsection{Unitary teaching method}

Currently, e-commerce is still confined to a finite classroom space in the campus, and still uses traditional teaching methods and teaching methods which are based in classroom and supplied by multimedia teaching and case teaching and enhance students' after-school exercises by arrangement job to consolidate the knowledge they have learned. Single teaching methods, one-way transfer of knowledge which lacks communication between teachers and students, passive dependence on teachers and classroom is not conducive to students to acquire practice and skills of analysing and solving problem.

\subsection{Obsolete teaching content}

Currently there are so many teaching materials related to e-commerce on the market. The dynamic feature of e-business e-commerce itself determines the materials to be inevitably lagging. Due to long update cycle, any introduction of e-commerce textbooks is to some extent out of touch with the latest practical produce business. Besides, in the Internet era, rapidly changing network environment is improving, and consumption habits of Internet users are also changing, and whether e-commerce features or functions will accordingly cause many changes. In addition, a large number of translation of foreign textbooks which cited in the majority of cases abroad, and our country far away to lead to weak operability and the lack of availability.

\subsection{Weak practicality}

Practical teaching has always been a focus of professional development of e-commerce, but the actual teaching effect is often unsatisfactory. Because carrying out the practice of teaching is often limited by external resources, so most universities select simulation practice teaching mode. E-commerce laboratory system is used for students to have simulation exercises. But under the passive, rigid and monotonous teaching atmosphere of learning, the results of this teaching mode of students get knowledge and ability to improve the obtained which are difficult to adapt to the demands of society, so the contradiction which students cannot satisfy the needs of e-commerce company talents occurs.

\subsection{Unitary test measurement}

Traditional courses generally only tested by the usual attendance and final exam. But actually e-commerce is 
a strong practical course, which is unable to fully examine student learning only depends on classroom performance and classroom content to grasp the situation assessment. If there is no corresponding assessment exercises and evaluation of class after class, it is difficult to be assured the teaching effect and guarantee students to upgrade their ability.

\section{TEACHING REFORM BASED ON MOOC}

There are many problems in the traditional e-commerce curriculum teaching, so it is necessary to make teaching reform. As a new model of learning and teaching, MOOC has a very good inspiration for the re-design curriculum model, redefining the role of teachers and students, as well as scores detection mechanisms in the e-commerce teaching reform.

Therefore, faced with the existing problems of e-commerce teaching curriculum, authors use related resources to make e-commerce teaching reform based on the MOOC model, and pilot at teaching classes. Specific expand from the following aspects.

\subsection{Refined Instructional Design}

It is generally about 45 minutes in the traditional e-commerce classroom, and set priorities or difficulties according to the outline requirements. For the boring and esoteric content in theory courses, students are generally more difficult to follow. MOOC teaching is characterized by the refinement of knowledge points, which will break the contents of knowledge down into the individual knowledge. Modular content just allows students to learn in stages.

Therefore, based on the features of e-commerce teaching and the points of students' interest, we can present teaching content in a modular fashion, taking the intrinsic link of knowledge as a basis for knowledge modules in series. For example, divide 45-minute course into 4-5 units, take every unit of knowledge as unit curriculum resource, regulate 10 minutes as the unit to select the appropriate topic, and design miniature learning units, let each unit represent a coherent concept. We display knowledge modules mainly by video. Among each knowledge module, we will design a lot of teaching interactive sessions in order to associate problems with knowledge points. For example, after each knowledge module, set a plurality of exercise task of different difficulty, so students can master the main course knowledge through repeated practice; set case analysis and discussion, linking theory with practice, to guide students to think deeply what they have learned in practical situations.

\subsection{Strengthen multi communication}

Different with traditional courses teaching, MOOC fully embodies the "self-learning" concept, and pro- vide learners with a variety of interactive community and build interactive participation mechanisms, which can encourage students to move from the past passive learners to active learners.

In e-commerce teaching, you can bring much course-related information together by MOOC platform and create a unique repository, such as programs database, libraries' database, to share resource and study interactively and extensively. Before class, students can through online repository, understand the relevant knowledge of e-commerce, preparing and thinking ahead; in class, teachers guide students to solve key issues and through learning activities, mobilize the enthusiasm of students to explore learning; after class, students relearn knowledge they have not yet mastered using the repository, and communicate with teachers and students based on cases. In addition, teachers can make expansion for the point of knowledge and ability, and introduce business projects related with e-commerce, so as to let students actually participate in the process of e-commerce project planning, implementation and so on. By introducing enterprise project into e-commerce courses, students can apply knowledge learned in class in real projects, and by involved in the execution of the project tasks, students can train e-commerce skills and learning ability, and gain the valuable actual combat experience, which lay the foundation for students' future jobs.

\subsection{Procedural examination mode}

According to the characteristics of e-commerce curriculum system, curriculum assessment should shift from the traditional "usually score + final score" model into a multi-stage process of assessment models. In each micro-learning units of MOOC, each class has a built-in testing and case discussion. Only those who past testing have the chance to enter the next phase of study, which will help to detect the effect of the class and ensure that students concentrate on what the teacher said and master each key point and difficult point. At the same time, evaluate the results of the task which students have submitted through various online learning platforms, form the final curriculum report and feedback to students. In addition, teachers arrange comprehensive assessment mission based on courses learning, to assess students' professional ability to grasp the situation. Certainly we can also organize teachers, peer teachers, students, and business to complete a comprehensive evaluation of the multi-task, so as to form a comprehensive and objective summative evaluation. Eventually combined with process evaluation, we can not only make dynamic and diverse but also objective and comprehensive evaluation on the students.

Through a series of educational reforms, students' classroom activity has been significantly improved. Students have a proficient grasp about knowledge. There are also some suggestions about relative plots 


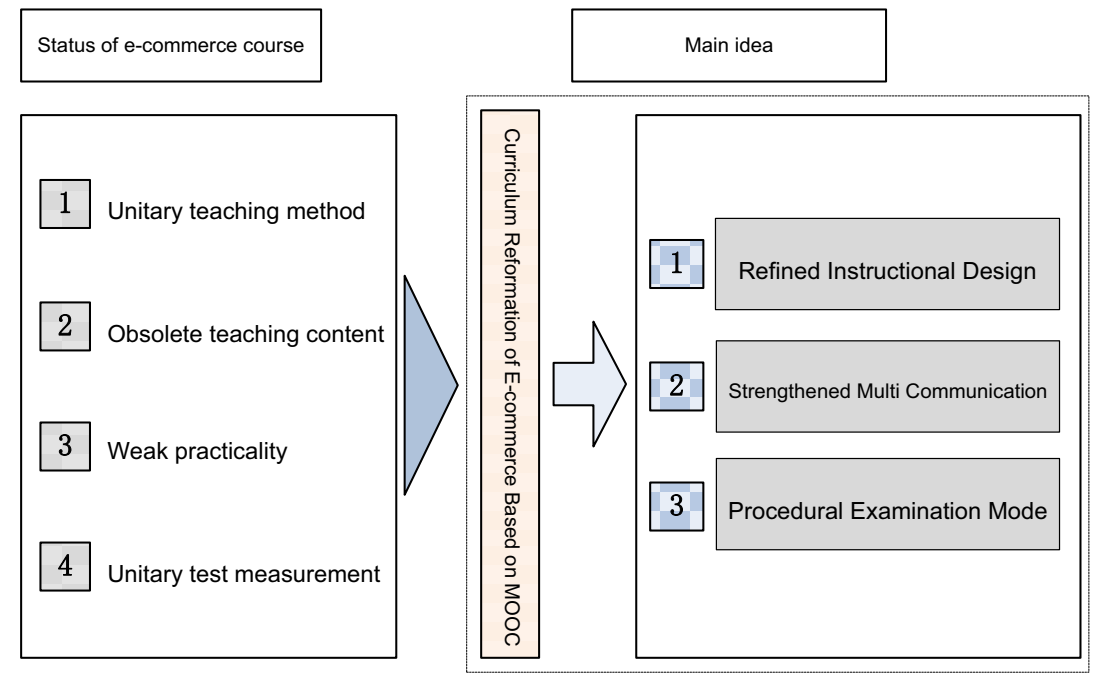

Figure 1.Curriculum reformation of e-commerce

settings, which greatly promote e-commerce teaching reform (see Figure 1).

\section{CONCLUSIONS}

E-commerce course, as a complex, cross-discipline, knowledge updates rapidly, so it is necessary for teachers to make timely adjustments combined with the discipline development and social development. Learning MOOC teaching methods, not only transfer the teacher's role from a lecturer and explainer to a motivator and inspirer, but also promote students to shift from learning knowledge passively to actively, which will effectively improve the teaching quality of e-commerce programs. This new way of teaching continues to progress and develop, and how to effectively make MOOC teaching mode combines with e-commerce teaching mode in order to explore MOOC teaching curriculum in line with the characteristics of e-commerce, still needs continuous exploration and improvement in teaching practice for a long time.

\section{ACKNOWLEDGEMENT}

This paper is sponsored by Humanity and Social Science Youth foundation of Ministry of Education of China (GN: 15YJCZH232)

\section{REFERENCES}

[1] Conole G. 2013. MOOCs as disruptive technologies: strategies for enhancing the learner experience and quality of MOOCs. Revista de Educación a Distancia, 39: $1-17$.

[2] Downes S. 2015. MOOC and mookies: The connectivism \& connective knowledge online course[EB/OL]. [2015-12-13]. http://www. downes.ca/presentation/197.
[3] Zhan Z., Fong P. S. W., Mei H., et al. 2015. Sustainability education in massive open online courses: A content analysis approach. Sustainability, 7(3): 2274-2300.

[4] Li Manli. 2013. Exploring the instructional design principles of MOOCs. Tsinghua Journal of Education, 4: $13-21$.

[5] Cui Xiaoping, Wang Lanzhong. 2015. Analysis of college English online teaching system based on MOOC. Modern Educational Technology, 4: 59-64.

[6] Li Liang. 2014. The research on national policies to supporting the development of MOOC. Modern Educational Technology, 24(5): 65-72.

[7] Zhang Xiao. 2015. Development and prospect of MOOC in China. Software Guide, 1: 156-158.

[8] He Bin. 2014. MOOC: Essence, current situation and prospect. Jiangsu Education Research, (1): 3-7.

[9] Head K. 2014. Are MOOCs the Future of General Education?. The Journal of General Education, 63(4): 244-255.

[10] Wang Wenli. 2013. The development of MOOC and the enlightenment to higher education. Jiangsu Higher Education, 2: 53-57.

[11] Zhou Q, Liu C, Xu J. 2015. The influence of "MOOC" on the cultivation of the students in the electrical engineering. Journal of Applied Science and Engineering Innovation, 2(7): 291-293.

[12] Wu Shuping. 2015. The research of cloud learning environment based on MOOC. Software Guide, 34(8): 119-123.

[13] Cui Guanxun. 2015. MOOC practice teaching platform based on cloud computing technology. Research and Exploration in Laboratory, 34(8): 119-123.

[14] Ma Xinqiang, Huang Yi, Cai Zongmo. 2014. Analysis of MOOC education platform technology and business model. Chongqing Higher Education Research, 2(1):5-9.

[15] Wang Shengqing, Feng Xuesong. 2015. Design and practice of MOOC training system for teacher's educational technology ability. Distance Education in China, (2): 56-60.

[16] Sadigh D, Seshia S A, Gupta M. 2012.Automating exercise generation: A step towards meeting the MOOC challenge for embedded systems. Proceedings of the Workshop on Embedded and Cyber-Physical Systems Education. ACM, 
[17] Guo P J, Kim J, Rubin R. 2014. How video production affects student engagement: An empirical study of MOOC videos. Proceedings of the first ACM Conference on Learning@scale conference. ACM,pp.41-50.

[18] Zhang Zhenhong, Liu Wen, Han Zhi. 2013. From OCW classroom to MOOC school: The return to the origin of learning. Modern Distance Education Research, (3): 20-27.

[19] Yang Wenyin, Ma Li, Zhou Lin, et al. 2015. Curriculum reformation of network engineering major for local university on MOOC. Computer Education, 5:24-28.

[20] Ma Wulin, Wu Zhongjie.2014. The enlightenment of MOOCs to college English curriculum design in China. Media in Foreign Language Instruction, (6): 40-45.

[21] Hu Jiehui, Wu Zhongiie. 2014. An empirical study on the MOOC-based college English flipped classroom in- structional model. Technology Enhanced Foreign Language Education. (6): 40-45.

[22] Whitmer J, Schiorring E, James P. 2014. Patterns of persistence: what engages students in a remedial English writing MOOC?. Proceedings of the Fourth International Conference on Learning Analytics and Knowledge. ACM, pp.279-280.

[23] Chi Yaqing, Song Ruiqiang, Li Zhentao. 2014. Effects of the MOOC on computer course teaching. Computer Engineering \& Science, 36(A01): 164-168.

[24] Liu Bingje. 2014. A study on reform of college computer teaching in MOOC era. Journal of Pingxiang College, 31(3): 116-118.

[25] Yuan Yali, Ye Yongfei. 2015. Computer experiment teaching reform based on MOOC in civil universities. Course Education Research, (24): 73-74. 